\title{
Characterization of Infection and Colonization of Strawberry Crowns by Colletotrichum acutatum
}

\author{
F.T. Arroyo, B. De los Santos and \\ F. Romero \\ IFAPA, Centro Las Torres-Tomejil \\ Alcalá del Rio, 41200 Sevilla \\ Spain
}

\author{
J. Moreno, P. Daza and J. Torreblanca \\ Dept. of Cell Biology \\ University of Seville \\ Av. Reina Mercedes 6, 41012 Seville \\ Spain
}

Keywords: anthracnose, colonization, infection process

\begin{abstract}
Strawberry anthracnose, caused by Colletotrichum acutatum J.H. Simmonds, is one of the most important diseases of this crop in Huelva (southwestern Spain). Lesions can occur on all parts of the plant but anthracnose crown rot is specially severe leading to wilt and death of plants. In this work, the infection and colonization process of $C$. acutatum on strawberry plants was studied. 'Camarosa' strawberry plants (highly susceptible to $C$. acutatum) were inoculated by applying $100 \mu \mathrm{l}$ droplets of a conidia suspension of the fungus on crowns, on buds and between second and third stipules. Plants were evaluated for response over a 30 days period. The severity of disease, estimated as percentage of plants showing symptoms on aerial parts, and the amount of infected crown tissues were determined at 2, 5, 10, 15, 20, 25 and 30 days after inoculation. Depending on the inoculation site the severity of anthracnose crown rot varied between plants. Moreover, an ultrastructural study of infected plants exhibiting anthracnose crown rot was carried out by transmission electron microscopy. The colonization of the crown tissues by intracellular and intercellular hyphae in the cortex, medulla and vascular system was observed resulting in cell colapse and necrosis.
\end{abstract}

\section{INTRODUCTION}

Strawberry anthracnose, caused by Colletotrichum acutatum, is an important disease in production areas in Huelva, southwestern Spain. Several species of Colletotrichum have been described causing strawberry anthracnose (Howard et al., 1992) C. acutatum being the most common species in Europe (Denoyes et al., 1996). Lesions can occur all over the plant, including roots, leaves, flowers, stolons, and fruits but is most devastating when the fungus invades the crown because it causes wilt and sudden death of the plant (Howard et al., 1992). Plants with anthracnose crown rot (ACR) may die in the nurseries or after being transplanted into fields. Crown rot is difficult to detect on plants at the moment of transplant because infections are in the initial stages before red streaks have developed in crowns. Plant death depends on the stage of infection at the moment of transplanting, and climatic conditions (Beraha and Wright, 1973; Howard et al., 1992; Leandro et al., 2003). These environmental conditions are common in Huelva causing plants losses of up to $80 \%$.

Host colonization and pathogenesis are well characterized for several species of Colletotrichum (Dickman, 2000). Also, the ultrastructure of the early stages of infection of starawberry petioles by $C$. acutatum describing the infection structures during the penetration phase have been reported by Arroyo et al. (2005). However, few studies have investigated the infection process of C. acutatum in strawberry crowns. Milholland (1982) described the invasion and colonization of crown tissues by $C$. fragariae using light microscopy. The aim of this study was to characterize the infection and colonization of strawberry crowns by $C$. acutatum in order to elucidate some aspects of anthracnose crown rot that remain poorly understood.

\section{MATERIALS AND METHODS}

'Camarosa' strawberry plants, highly susceptible to C. acutatum (De los Santos, 
1998), were planted in $10.5 \times 13.5 \mathrm{~cm}$ plastic pots containing sterilised peat (KlansmannDeilmann, Geeste, Germany) and grown for 30 days, before inoculation with $C$. acutatum, in a greenhouse maintained at $25^{\circ} \mathrm{C}$ day $/ 15^{\circ} \mathrm{C}$ night $\pm 5^{\circ} \mathrm{C}$.

C. acutatum isolate CECT-20240 was used in this study. The fungus was grown on potato dextrose agar (PDA, DIFCO) for $7 \mathrm{~d}$ at $25^{\circ} \mathrm{C}$ under continuous fluorescent light. Conidial suspensions for inoculation were prepared by flooding the culture plates with 4$5 \mathrm{ml}$ of sterile distilled water, scraping the colony surface with a scalpel, and filtering the suspension through sterile cheesecloth. The concentration was adjusted to $1 \times 10^{6}$ conidia $\mathrm{ml}^{-1}$ using a hemocytometer. Strawberry plants were inoculated on three different sites: directly on crowns, on buds and between second and third stipules by applying $100 \mu \mathrm{l}$ droplets of conidial suspension. For each type of inoculation eight plants were used. Inoculated plants were enclosed in plastic bags for $48 \mathrm{~h}$ to maintain high relative humidity and were incubated in a growth chamber at $25^{\circ} \mathrm{C}$, with a $16 \mathrm{~h}$ photoperiod beneath fluorescent light. Control plants were treated with $100 \mu \mathrm{l}$ of sterile distilled water. Disease incidence was evaluated daily. Also, the presence of pathogen in crown tissues was quantified by isolating the fungus from inoculated crowns at different times. Furthermore, the infection process of $C$. acutatum into crown tissues was studied by using light and electron microscopy. Material was prepared as described by Arroyo et al. (2005).

\section{RESULTS AND DISCUSSION}

ACR symptoms were observed at 5 days post inoculation (dpi) in plants inoculated directly on crowns affecting to $50 \%$ of the plants. The percentage rise to $100 \%$ at 10 dpi (Table 1). Wilting and death of the plants inoculated in this way was observed at $10 \mathrm{dpi}$ affecting to $25 \%$ of them. The percentage of dead plants rose to $50 \%$ at $20 \mathrm{dpi}$ and to $75 \%$ at 30 dpi (Table 2). Small flecks or lesions of 3 to $5 \mathrm{~mm}$ length developed on the inoculated area. Longitudinal sections of infected crowns revealed reddish brown lesions similar to the those reported by Arroyo (2004). However, in plants inoculated on buds and between stipules, ACR symptoms were detected at 30 dpi affecting to $25 \%$ of the plants (Table 1). In plants inoculated on buds, brown dark lesions were observed causing foliar deformation. In plants inoculated between stipules, orange lesions were detected on the inoculated area. No wilting or plant death was observed in plants inoculated on buds and between stipules (Table 2). The percentage of infected crown was higher in plants inoculated directly on crowns than in plants inoculated on buds or between stipules (Table 3 ). This means that the invasion of the crown tissues by the fungus was much more advanced in these plants and it can be related to visible symptoms on aerial parts.

Germination and penetration of crown tissues occurred after 12-24 hpi (Arroyo et al., 2005). The invading hyphae grew intercellularly in the cortex causing collapse of the cell walls. At 3 dpi, several cortex layers had collapsed with hyphae inside the cells. The fungus spread both intercellularly and intracellularly throughout the parenchyma. At $5 \mathrm{dpi}$, necrosis of the cortex was extensive and the vascular bundles had been invaded. The phloem and xylem vessel elements were filled with intracellular hyphae, but there was no breakdown of xylem vessel walls. The fungus progressed into the crown tissues invading the vascular tissue and pith. The colonization and invasion of vascular tissue could explain the wilting of the aerial parts of the plant and eventually, necrosis and collapse of cells could cause the death of the plant.

\section{CONCLUSIONS}

Anthracnose crown rot is difficult to detect because it shows a slow development or progress. Therefore, the wilting and sudden death of the strawberry plant in a short time after being transplanted, less to 30 days, occurs in those plants whose crowns are just infected when they are planted. However, if the infection by Colletotrichum acutatum comes from the buds or from the stipules the ACR symptoms are displayed at least at 30 dpi. These symptoms are very reduced and no wilt or plant death was recorded in this period. 


\section{Literature Cited}

Arroyo, F.T. 2004. Caracterización del proceso de infección de Colletotrichum acutatum Simmonds en plantas de fresa (Fragaria xananassa Duch.): Estructura y Ultraestructura. Phd. thesis. University of Seville.

Arroyo, F.T., Moreno, J., García-Herdugo, G., De los Santos, B., Barrau, C., Porras, M., Blanco, C. and Romero, F. 2005. Ultrastructure of the early stages of Colletotrichum acutatum infection of strawberry tissues. Can. J. Bot. 83:491-500.

Beraha, L. and Wright, R. 1973. A new anthracnose of strawberry caused by Colletotrichum dematium. European Journal of Plant Pathology. 57:445-448.

Denoyes-Rothan, B., Guerin, G., Nourriseau, J.G., Morzieres, J.P., Baudry, A., Lesgourges, D. and Clerjeau, M. 1996. Situation de l'anthracnose du fraisier en France. PHM. Rev. Hortic. 371:23-27.

Dickman, M.B. 2000. Colletotrichum. Fungal Pathology Ed. J.W. Kronstad.

Howard, C.M., Maas, J.L., Chandler, C.K. and Albregts, E.E. 1992. Anthracnose of strawberry caused by the Colletotrichum complex in Florida. Plant Dis. 76:976-981.

Leandro, L.F.S., Gleason, M.L., Nutter, F.W., Wegulo, S.N. and Dixon, P.A. 2003. Influence of temperature and wetness duration on conidia and appressoria of Colletotrichum acutatum on symptomless strawberry leaves. Phytopathology 93(4):513-520.

Milholland, R.D. 1982. Histopathology of strawberry infected with Colletotrichum fragariae. Phytopathology 72:1434-1439.

\section{Tables}

Table 1. Average percentage of 'Camarosa' strawberry plants showing ACR symptoms after 30 days. $\mathrm{CD}$, plants inoculated directly on crowns; $\mathrm{CB}$, plants inoculated on buds, and CE, plant inoculated between $2^{\text {nd }}$ and $3^{\text {rd }}$ stipules.

\begin{tabular}{lccccccc}
\hline Inoculation & \multicolumn{7}{c}{ Days post-inoculation } \\
\cline { 2 - 8 } sites & 2 & 5 & 10 & 15 & 20 & 25 & 30 \\
\hline $\mathrm{CD}$ & 0 & 50 & 100 & 100 & 100 & 100 & 100 \\
$\mathrm{CB}$ & 0 & 0 & 0 & 0 & 0 & 0 & 25 \\
$\mathrm{CE}$ & 0 & 0 & 0 & 0 & 0 & 0 & 25 \\
Control & 0 & 0 & 0 & 0 & 0 & 0 & 0 \\
\hline
\end{tabular}

Table 2. Average percentage of dead plants by ACR inoculated with C. acutatum. CD, plants inoculated directly on crowns; $\mathrm{CB}$, plants inoculated on buds, and $\mathrm{CE}$, plant inoculated between $2^{\text {nd }}$ and $3^{\text {rd }}$ stipules.

\begin{tabular}{lccccccc}
\hline Inoculation & \multicolumn{7}{c}{ Days post-inoculation } \\
\cline { 2 - 8 } sites & 2 & 5 & 10 & 15 & 20 & 25 & 30 \\
\hline $\mathrm{CD}$ & 0 & 0 & 25 & 25 & 50 & 75 & 75 \\
$\mathrm{CB}$ & 0 & 0 & 0 & 0 & 0 & 0 & 0 \\
$\mathrm{CE}$ & 0 & 0 & 0 & 0 & 0 & 0 & 0 \\
Control & 0 & 0 & 0 & 0 & 0 & 0 & 0 \\
\hline
\end{tabular}

